\title{
Prevalence and risk factors for urinary incontinence in bitches five years after ovariohysterectomy
}

\author{
[Prevalência e fatores de risco para incontinência urinária em cadelas \\ cinco anos após ovário histerectomia ] \\ B. Leupolt $^{1}$, C.R. Barbieri ${ }^{1}$, L. Jesus ${ }^{2}$, A.G. Pöppl $l^{3 *}$ \\ ${ }^{1}$ Aluna de graduação - Faculdade de Veterinária - UFRGS - Porto Alegre, RS \\ ${ }^{2}$ Aluna de pós-graduação - UFRGS - Porto Alegre, RS \\ ${ }^{3}$ Faculdade de Veterinária - UFRGS - Porto Alegre, RS
}

\begin{abstract}
Ovariohysterectomy (OHE) is the most performed elective surgery in veterinary medicine. Although this procedure brings benefits both to the animal and public health, acquired urinary incontinence is a possible complication resultant from it. The aim of this study was to determine the prevalence of urinary incontinence and evaluate size, breed, and time of surgery as risk factors in a population of spayed female dogs in the Hospital de Clínicas Veterinárias da Universidade Federal do Rio Grande do Sul, in the year of 2013, through the use of a multiple-choice screening instrument. Identified estimated prevalence was $11.27 \%$ and main risk factors were as follows: large size ( $\mathrm{OR}=7.12 \mathrm{IC} 95 \%=1.42-35.67)$, Rottweiler breed $(\mathrm{OR}=8.92$; IC95\% $=5.25-15.15)$, Pit-bull breed $(\mathrm{OR}=4.14$; IC95\% $=2.19-7.83)$, and Labrador breed $(\mathrm{OR}=2.73$; IC95\% $=1.53-4.87)$. Time of surgery was not considered a risk factor for urinary incontinence in this population $(\mathrm{OR}=1.45$; IC95\% $=0.86-2.40)$. Even though most owners reported a small impact on their relationship with the animal, urinary incontinence hazard should be addressed before spaying.
\end{abstract}

Keywords: spaying, castration, urethral sphincter mechanism incompetence

\section{RESUMO}

A ovário-histerectomia (OHE) é a cirurgia eletiva mais realizada em medicina veterinária. Embora seja um procedimento que beneficie a saúde pública e do animal, a incontinência urinária adquirida é uma complicação possível resultante desse procedimento. O objetivo deste estudo foi determinar a prevalência de incontinência urinária e avaliar porte, raça e momento da castração como fatores de risco em uma população de cadelas castradas no HCV/UFRGS, no ano de 2013, através do uso de um instrumento de triagem de múltipla escolha. A prevalência estimada foi de 11,27\% e os principais fatores de risco foram: grande porte $(O R=7,12$ IC95\% = 1,42 - 35,67), raça Rottweiler $(O R=8,92 ;$ IC95\% = 5,25 - 15,15), raça Pitbull $(O R=4,14 ;$ IC95\% = 2,19 - 7,83) e raça Labrador $(O R=2,73 ; I C 95 \%=1,53-4,87)$. O tempo da cirurgia não foi considerado fator de risco para incontinência urinária nessa população $(O R=1,45$; $I C 95 \%=0,86$ - 2,40). Embora a maioria dos proprietários tenha relatado um pequeno impacto no relacionamento com o animal, a possibilidade de incontinência urinária deve ser devidamente discutida antes da castração.

Palavras-chave: castração, gonadectomia, incompetência do mecanismo do esfíncter uretral

\section{INTRODUCTION}

Ovariohysterectomy (OHE) is the most performed elective surgery in veterinary medicine (Concannon and Meyers-Wallen, 1991). Among indications for $\mathrm{OHE}$ in bitches, besides population control, are benefits in reduction of reproductive tract diseases, reduction of mammary and reproductive tract neoplasia risk, control of sexually transmitted diseases, as well as diabetes mellitus potential prevention (Hedlund, 2012; Pöppl et al., 2017). Despite being considered a recommended procedure, OHE may be associated with a series of post-surgical complications.

Recebido em 7 de maio de 2020

Aceito em 17 de outubro de 2020

*Autor para correspondência (corresponding author)

E-mail: gomespoppl@hotmail.com 
Among those, urologic ones have often been reported, with urinary incontinence (UI) being considered a possible complication of spaying in bitches (Hoelzler and Lidbetter, 2004; Van Goethem et al., 2006; Applegate et al., 2018; Acierno and Labato, 2019).

Post-OHE urinary incontinence affects between 3.5\% (De Cesare et al., 2013; Forsee et al., 2013) and $20.1 \%$ (Arnold et al., 1989) of bitches undergoing spaying surgery (Applegate et al., 2018; Acierno and Labato, 2019). Besides being vulnerable to sanitary and management problems, affected animals become more predisposed to skin diseases and lower urinary tract infection (Gregory, 1994). Therefore, post-OHE urinary incontinence impacts in both animals and their owner's quality of life. With a mean development time of three to four years (Arnold et al., 1989; Byron et al., 2017; Pegram et al., 2019), urinary incontinence is one of main isolated causes for animal abandonment in North American shelters (Applegate et al., 2018). However, data paucity regarding this topic can be found in Brazil. The aim of this study was to investigate cumulative prevalence of post-OHE urinary incontinence in the population of female dogs spayed five years ago at Hospital de Clínicas Veterinárias (HCV) da Universidade Federal do Rio Grande do Sul (UFRGS), and to determine possible risk factors for affection occurrence.

\section{MATERIALS AND METHODS}

Trans-sectional study to define prevalence of urinary incontinence among bitches spayed five years ago, and possible related risk factors such as dog's size, breed, and time of spaying. This study was approved by the Ethics Committee for Animal Use of the Universidade Federal do Rio Grande do Sul (protocol 36786).

Candidate patients to participate in the study were selected from the Medical and Statistical Archive Service's system from HCV/UFRGS. To ensure a five-year period after $\mathrm{OHE}$ and the possible onset of UI, all the 291 registers of bitches spayed at $\mathrm{HCV}$ five years before the study was conducted were considered eligible to be included. Based on largest UI prevalence recorded in literature of $20 \%$ (Arnold et al., 1989), an N-sample of 133 animals was estimated using Epi Info calculator ${ }^{\mathrm{TM}}$ with a $95 \%$ statistical significance and $5 \%$ error margin.
In order to find urinary incontinence (UI) prevalence in spayed female dogs, owners of bitches spayed five years before were contacted by phone so as to determine problem's occurrence through a screening instrument for evidencing and characterization of the UI's intensity using questions with multiple choice answers. All owners were informed with regards to the study objective and how they had been selected to participate, and thus their consent to participate in research was assumed as they answered the questions.

The screening instrument established the presence of urinary incontinence, time elapsed from spaying and beginning of clinical signs, impact of incontinence in owner's routine as well as desire to pursue UI treatment. These aspects were assessed through multiple choice questions: 1) Does your dog drip urine while walking? 2) Does your dog lose urine while on your lap? 3) Do you notice the bed or places where the animal lies soiled with urine? 4) How many times a day does your dog urinate? 5) Which of the alternatives below better describes the micturition pattern of your dog? 6) Do you consider your dog to be urinary incontinent (loss of urine control, involuntary urine loss)? If the owner considered their dog urinary incontinent, a few more questions were asked: 7) How long has this problem been present? 8) Is it necessary to use any kind of toilet mat or diapers? If so, how many times a day does it need to be changed? 9) How much does this problem affect your routine at home? 10) Have you ever looked for urinary incontinence treatment for the $\operatorname{dog}$ ? If so, was it successful? 11) Would you like your dog to be treated for this condition?

In those cases which the occurrence of UI was characterized, a quantitative scale (1 to 10 points) was elaborated according to clinical signs severity reported in questions 1 to 3 to categorize UI's clinical presentation severity. Regarding relevance of clinical sign, points were distributed into "no relevance" (zero point), "little relevance" (one point), "moderate relevance" (two points), "severe" (three points) and "very severe" (four points). Based on this score, all animals classified as having post-spaying UI were categorized in relation to urinary continence compromise level. Animals with a total score between 1 and 4 points in the scale of severity were categorized as "little compromise", those between 5 and 7 points were 
categorized as "moderate compromise", and animals ranging from eight to 10 points were categorized as "severe compromise".

To determine potential risk factors related to urinary incontinence occurrence in this population, previous risk factors reported in literature (age at OHE surgery, dog's size, and dog's breed) were evaluated through the patient's medical records. To categorize age at OHE, dogs were categorized as spayed before two years-old, or with two or more years-old. Regarding dog's size, patients were categorized as follows: Toy < $5 \mathrm{~kg}$ (T Group); Small (6-10kg) (S Group); Medium (11-25kg) (M Group); Large (26-45kg) (L Group); and Giant (> 46kg) (G Group). Patient's breeds represented among UI cases were also considered in risk factor analysis. Univariate odds ratio (OR) and respective $95 \%$ confidence interval $(95 \% \mathrm{CI})$ analysis was performed for each variable surveyed. Exact Fischer's test was performed to determine $\mathrm{P}$-value, which was considered significant if $P<0.05$. The package Prism GraphPad version 6.0 was used to perform statistical analysis.

\section{RESULTS}

In order to achieve the sample number of $133 \mathrm{dog}$ owners willing to participate in the study, 275 phone calls were made. Main reasons for the low efficiency in getting owners to take part in the study were out-of-date registration data (number changes) and lack of interest to collaborate with the research. Of the 133 dogs whose owners took part in the research, 19 owners reported abnormalities in urination. However, four animals were not considered as post-spaying urinary incontinent due to a history of other alterations, such as spinal cord injury (1), intervertebral disc disease (IVDD) (2) and urolithiasis (1) that could justify the UI (Acierno and Labato, 2019; Less, 2004). Hence, spayed females' UI estimated prevalence in population assessed was $11.27 \%$ (15 animals). Table 1 shows in details study participants' breeds distribution between urinary continent and urinary incontinent ones.

Regarding size distribution of the 133 patients evaluated, most patients were categorized as small-sized dogs (S Group 43.6\% - $n=58$ ). Medium-sized dogs (M Group) represented $27.8 \%(n=37)$ of the patients in the study, another $23.3 \%(n=31)$ were represented by dogs in the Toy Group, while only $5.3 \%(n=7)$ bitches were classified as Large (L group). No bitch was categorized in the Giant Group. Despite the L Group being the smallest, the UI prevalence varied among groups, and was more often evidenced in large dogs. Figure 1 shows comparative UI frequency in each group. The $\mathrm{T}$ Group showed a $3.25 \%(n=1)$ UI prevalence, while in $\mathrm{S}$ and $\mathrm{M}$ Groups prevalence increased to $10.3 \% \quad(n=6)$ and $13.5 \% \quad(n=5)$, respectively. Large group showed a $42.9 \% \quad(n=3)$ UI prevalence.

Table 1. Patients' breed distribution among study participants according to urinary continence status

\begin{tabular}{lcccc}
\multicolumn{1}{c}{ Breed } & Post-spaying UI & Other causes UI & Urinary continent & Total \\
\hline Australian Cattle Dog & - & - & 1 & 1 \\
Border Collie & - & - & 2 & 2 \\
Chow Chow & - & - & 1 & 1 \\
Dachshund & 1 & 1 & 4 & 6 \\
Labrador & 1 & - & 3 & 4 \\
Lhasa Apso & - & - & 3 & 3 \\
Mongrel & 6 & 2 & 62 & 70 \\
Pinscher & - & - & 4 & 4 \\
Pit Bull & 1 & - & 2 & 3 \\
Poodle & 2 & - & 12 & 14 \\
Rottweiler & 2 & 1 & 2 & 5 \\
Schnauzer & - & - & 1 & 1 \\
Shih Tzu & 1 & - & 2 & 11 \\
Terrier Brasileiro & - & - & 5 & 2 \\
Yorkshire & 1 & - & 118 & 6 \\
Total & 15 & 4 & & 133 \\
\hline
\end{tabular}

* UI = urinary incontinence 
There was a statistically significant association between post-spaying incontinence and Large size group $(\mathrm{OR}=7.12$ IC95\% $=1.42-35.67)$ when compared to other groups with a $<25 \mathrm{Kg}$ size.
When the Large size group was compared only to Small and Toy ones, odds ratio for large size was even greater $(\mathrm{OR}=8.78$; IC95\% $=1.63-47.33)$.

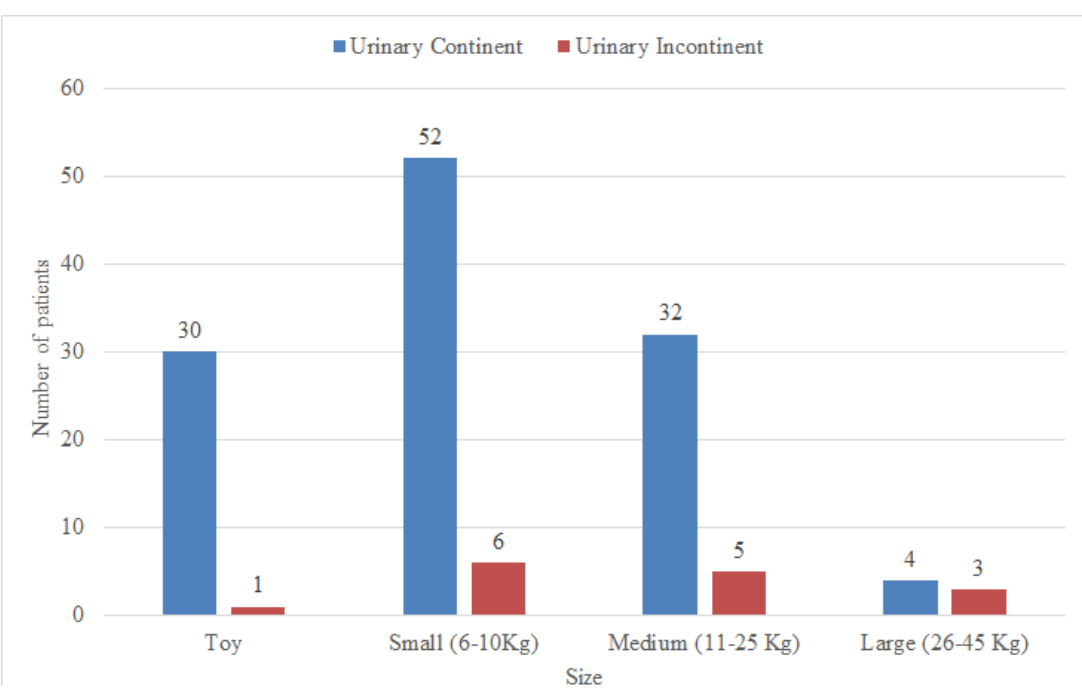

Figure 1. Graphic distribution of canine patients' number with or without urinary incontinence five years after ovariohysterectomy distributed by group of size.

Incontinent breeds described in the study were Yorkshire $(n=1)$, Dachshund $(n=1)$, Shih Tzu $(\mathrm{n}=1)$, Pit bull $(\mathrm{n}=1)$, Labrador $(\mathrm{n}=1)$, Poodle $(n=2)$, Rottweiler $(n=2)$, and Mongrel $(n=6)$. Animals considered urinary incontinent were 8.92 times more likely to belong to Rottweiler breed $(\mathrm{OR}=8.92 ;$ IC95\% $=5.25-15.15)$ when compared to other breeds. When chance ratio of incontinent dogs being of Pit-bull breed was assessed, these dogs had 4.14 times more chance to belong to this breed when compared to others $(\mathrm{OR}=4.14 ; \mathrm{IC} 95 \%=2.19-7.83)$. Incontinent bitches were observed to have had 2.73 times more chances to be Labrador breed $(\mathrm{OR}=2.73$; IC95\% $=1.53-4.87$ ) when compared to other breeds in the study.
Concerning age at spaying, $51.8 \%$ of the female dogs $(n=69)$ in this study were spayed with less than two years old and $48.2 \%(n=64)$ with more than two years. When comparing the distribution of post-spaying UI cases to the age at spaying, it was observed that $60 \% \quad(n=9)$ of animals considered to have UI $(n=15)$ fell in the group that was spayed with less than two years of age. Despite that, spaying before two years of age was not considered more frequent among incontinent bitches $(\mathrm{OR}=1.45$; IC95\% $=0.86-2.4)$. Odds ratio analyses performed for risk involved in size, breed, and time after spaying as risk factors for UI in female dogs are shown in Table 2.

Table 2. Odds ratio analysis and respective $95 \%$ confidence intervals of post-spaying urinary incontinence risk factors studied regarding size, breed, and age at spaying. Statically significant risk factors in univariate analysis are identified by an asterisk

\begin{tabular}{lcc}
\multicolumn{1}{c}{ Factor Analyzed } & Odds Ratio & 95\% Confidence Interval \\
\hline Large size $v s$. Small/Toy* & 8.78 & $1.63-47.33$ \\
Large size $v s$. Medium/Small/Toy* & 7.12 & $1.42-35.67$ \\
Medium size $v s$. Small/Toy & 1.98 & $0.54-6.17$ \\
Rottweiler $v s$. Mongrel dogs* & 10.83 & $1.28-81.55$ \\
Rottweiler $v s$. Other breeds* & 8.92 & $5.25-15.15$ \\
Pitt Bull $v s$. Other breeds* & 4.14 & $2.19-7.83$ \\
Labrador $v s$. Other breeds* & 2.73 & $1.53-4.87$ \\
Age at spaying <2 years $v s .>2$ years & 1.45 & $0.86-2.40$ \\
\hline
\end{tabular}


In this study, clinical manifestations of postspaying UI have developed less than three years after the surgery in $80 \%(n=12)$ of cases, and among these, $25 \%(n=3)$ developed signs in the first 30 days after surgery. Other $20 \%(n=3)$ of dog owners reported clinical manifestations began more than three years after spaying. Concerning time for the development of affection, cumulative prevalence of UI was calculated according to time post-surgery. UI prevalence after one year of spaying was $2.26 \%$. Prevalence of the development of UI within three years after the surgery was $9.01 \%$, culminating in a final cumulative prevalence of $11.27 \%$ five years after spaying. Only those animals identified as likely to have UI $(n=15)$ were included in the second part of the instrument, which accessed UI impact in owner's life. Regarding use of hygiene pads to minimize problems with the urinary incontinent patient's management, $100 \%$ of dog owners, when asked, said they did not use such pads, since they coped well with the problem.

When it comes to the impact of the dog's UI in the owner's routine ( $n=15$ owners), $33.3 \%(n=5)$ of those owners interviewed answered "Does not affect", whereas $20 \%(n=3)$ reported "Affected a little, bothered them, but they could deal with the problem", and another $46.6 \%(\mathrm{n}=7)$ of owners said, "Affected a little, if they could solve this problem it would be good". When asked whether the animal had already been treated for the problem, none of the owners reported having looked for treatment for the bitches' UI.

To assess the screening instrument's accuracy, the variable "presence of clinical signs for postspaying UI" determined based on answers to questions 1 to 3 had its correlation verified with answer to question 6, which assessed the variable "classification of the animal regarding its continence". A percentage of positive correlation between answers of $88 \%$ was found. Of the $12 \%$ of owners whose answers had a negative correlation, all animals were classified as urinary continent, despite having presented some positive answers to presence of UI clinical signs.

Animals classified as having post-spaying UI were further categorized regarding their compromise. One third $(n=5)$ of incontinent dogs were categorized as "Little compromise"; $46.6 \%$ $(\mathrm{n}=7)$, as "Moderate compromise", and $20 \%(\mathrm{n}=3)$ of those with UI were categorized as "Severe compromise". All those considered as having severe compromise belonged to the $\mathrm{M}$ group. Table 3 shows individual data of each patient in relation to their size, time between $\mathrm{OHE}$ and onset of UI, and level of compromise based on the scale of severity relevance of the problem's manifestation.

Table 3. Post-spaying urinary incontinence cases identified in the study and their relationship with size, breed, age at ovariohysterectomy, time between ovariohysterectomy and urinary incontinence beginning, incontinence gravity score, and commitment level

\begin{tabular}{|c|c|c|c|c|c|c|}
\hline Patient & Size & Breed & $\begin{array}{c}\text { Age at OHE } \\
\text { (years) }\end{array}$ & $\begin{array}{c}\text { Time between } \\
\text { OHE and UI }\end{array}$ & $\begin{array}{c}\text { Gravity } \\
\text { Score (1- } \\
10)\end{array}$ & Commitment level \\
\hline 1 & Small & Poodle & 0.4 & $>3$ years & 6 & Moderate \\
\hline 2 & Small & Dachshund & 4 & $<3$ years & 6 & Moderate \\
\hline 3 & Small & Mongrel & 1 & $<1$ year & 1 & Little \\
\hline 4 & Small & Poodle & 2 & $<3$ years & 5 & Moderate \\
\hline 5 & Medium & Pit Bull & 3 & $<3$ years & 10 & Severe \\
\hline 6 & Large & Labrador & 0.4 & $<3$ years & 9 & Severe \\
\hline 7 & Small & Shih Tzu & 6 & $<3$ years & 6 & Moderate \\
\hline 8 & Large & Rottweiler & 6 & $<3$ years & 6 & Moderate \\
\hline 9 & Medium & Mongrel & 2 & $<1$ year & 4 & Little \\
\hline 10 & Medium & Mongrel & 1 & $>3$ years & 3 & Little \\
\hline 11 & Large & Rottweiler & 6 & $<3$ years & 6 & Moderate \\
\hline 12 & Small & Mongrel & 2 & $<3$ years & 3 & Little \\
\hline 13 & Medium & Mongrel & 5 & $<3$ years & 6 & Moderate \\
\hline 14 & Medium & Mongrel & 1 & $<1$ year & 10 & Severe \\
\hline 15 & Toy & Yorkshire & 1 & $>3$ years & 2 & Little \\
\hline
\end{tabular}

* $\mathrm{OHE}=$ ovariohysterectomy, UI = urinary incontinence 


\section{DISCUSSION}

Post-spaying UI prevalence (11.27\%) found in the female dogs' population in this study five years after surgery was considered significantly lower than reported by Arnold et al. (1989), who found a $20.1 \%$ prevalence in his study. However, our results were higher than those of two recent studies, which found a 3.5\% (De Cesare et al., 2013) and $5.12 \%$ (Forsee et al., 2013) UI prevalence in bitches after spaying. Both also based on the analysis of owner's answers to an assessment instrument. Thus, number of cases found in our study falls between those demonstrated in both studies that are the base for discussion of UI prevalence in available literature (Arnold et al., 1989; Forsee et al., 2013; Applegate et al., 2018), and it was three times higher than the only UI prevalence study's result found in Brazil (De Cesare et al., 2013). A relevant differential of our results was to have assessed UI compromise level of affected bitches by means of a gravity score. Despite different studies having previously studied UI prevalence and risk factors (Arnold et al. (1989; De Cesare et al., 2013; Forsee et al., 2013; Byron et al., 2017; Pegram et al., 2019), none of those studies classified UI gravity.

According to Arnold et al. (1989) this high prevalence $(20 \%)$ is seemingly different from reported by owners of incontinent dogs, since it can be difficult for owners to notice clinical signs. Many of these dogs presented clinical signs of post-spaying positional urinary incontinence, meaning they usually present loss of urinary control when they are recumbent due to increased bladder pressure from position (Arnold et al. (1989; Acierno and Labato, 2019). Nevertheless, in our study, $86.6 \%(n=13)$ of owners whose animals were classified as urinary incontinent positively stated having already observed clinical signs when the animal was recumbent. This study demonstrated most dog owners observed the most evident clinical sign of UI whenever it was present. Besides, the positive correlation between answers obtained and clinical signs $(r=0.88)$ was considered a strong correlation (Medronho et al., 2009) and argues in favor of internal consistency of the screening instrument developed.

As a rule, the greater the size of females (body weight $>15 \mathrm{Kg}$ ), the greater the likelihood to develop post-spaying UI when compared to small-sized females (body weight $<15 \mathrm{Kg}$ ) (Forsee et al., 2013). According to De Bleser et al., 2011, a body weight of over $10 \mathrm{~kg}$ increases by four times the chance to develop UI as a sequela of spaying in bitches, and a prevalence of up to $30 \%$ of UI in female dogs over $20 \mathrm{~kg}$ was reported, with patient's size being an important risk factor (Byron, 2015; Byron et al., 2017). Our study has found the proportion of incontinent bitches increased gradually as animal's size became larger, which is in accordance with the aforementioned observations. Byron et al., 2017) also documented an increased risk for UI in bitches over $25 \mathrm{~kg}$; however, their findings suggested neutering these bitches later in their first year reduces this hazard, an effect not observed in smaller patients. Nevertheless, aging and increasing bodyweight were associated with higher risk for UI after spaying (Pregram et al., 2019).

For the same reason as stated for size, but eventually for genetic reasons as well, large-sized breeds have shown a greater prevalence for UI development. Breeds such as Dobermann, Schnauzer, Rottweiler, Irish Setter, and Old English Sheepdog are more likely to develop UI (Arnold et al., 1989; Holt and Thrusfield, 1993). In our study, statistically significant associations were found between UI manifestation and Rottweiler breed. However, greater chance of incontinent bitches being either Labradors or Pit Bulls does not seem to be justified by breed predisposition, but rather, size and popularity of the aforementioned breeds in dogs' population treated at $\mathrm{HCV}$. Greater predisposition regarding breeds of larger size and heavier weight is believed to be due to a more intense intraabdominal pressure, along with urethral sphincter mechanism incompetence (USMI), leading to the onset of incontinence (Byron et al., 2017).

Concerning relationship between age at spaying and the development of UI, there was no statistical significance between age at spaying and the onset of post-spaying UI in our study. Nevertheless, conflicting reports regarding a higher predisposition for bitches spayed before the first heat can be found in literature (Holt and Thrusfield, 1993; Beauvais et al., 2012). In Forsee's et al. study (2013), though, they defended the hypothesis there is no association between age at OHE and the development of UI. Also, Howe et al. (2001) did not document any predisposition 
effect of prepuberal gonadectomy on UI occurrence after 48 months follow up. In their research, Pregram et al. (2019) show age at spay was not associated with UI later in life.

Five-year interval between spaying and OHE was stablished based on literature's subject, since according to Arnold et al. (1989), 75\% of affected dogs develop UI up to three years after the procedure. In our study, $80 \% \quad(n=12)$ of the females classified as having post-spaying UI developed clinical signs less than three years after the surgery, in accordance with data reported in previous studies. Development of UI in spayed dogs varies from soon after surgery to up to twelve years after the procedure (Arnold et al., 1989), meaning some of the dogs assessed could still develop UI in upcoming years. Therefore, a longer longitudinal follow-up study could increase UI's prevalence in the sample evaluated.

The severity scale of UI was a way to make the owner's assessment of their pet's condition less subjective. The scale was based on clinical signs of UI in spayed females described in the literature consulted (Arnold et al. (1989; Hoelzler and Lidbetter, 2004; Less, 2004; Voorwald et al., 2010; Forsee et al., 2013). Regarding severity of the disease, $20 \%(n=3)$ of the bitches with UI were categorized with severe compromise, and these were medium-sized dogs. According to Forsee et al., (2013), bitches with larger sizes are about seven times more likely to develop UI. Based on this assumption, and on top of predisposition already mentioned in literature regarding development of UI, it is possible to hypothesize that an association exists between severity of postspaying UI and larger-sized bitches. As for the group of animals categorized as little compromise $(n=5)$ in the scale, $60 \%(n=3)$ were small-sized or toy dogs, and their answers generally scored little or no severity in the scale.

Regarding how much UI affected life and routine of dog owners, most of the interviewees surprisingly stated it had only a small impact on them. This finding contrasts with UI potential to weaken relationship between owner and pet as suggested by Forsee et al., 2013. Despite measurement bias possibility given the study design, UI is a worthy cause of animal abandonment in USA and must be addressed with dog owners before OHE surgery, especially in large-sized animals (Applegate et al., 2018).
Nevertheless, half of interviewed owners reported desire to solve the problem if possible.

Concerning limitations of the study, despite the possibility of incontinent patient selection bias due to the study design (Less, 2004; Medronho et al., 2009), evidencing of urinary incontinence in clinical practice routine is often based on owner's main complaint. Likewise, patients with little incontinence may eventually not have been included in the study due to owner's lack of problem perception. Another important limitation was sample size, since despite the considerable number of patients submitted to the screening instrument of post-spaying urinary incontinence, a larger sample size including patients spayed longer than five years ago could eventually change the prevalence reported here (Forsee et al., 2013).

\section{CONCLUSIONS}

Although prevalence of UI fell within those previously described in other studies performed abroad, at least one out of each ten bitches spayed may become urinary incontinent after OHE, and this hazard was even greater in large breeds. This possible neutering complication must be considered, especially when dealing with largesized females or predisposed breeds. However, age at neutering did not show influence on the occurrence of UI. Most cases herein documented were well tolerated by their owners.

\section{ACKNOWLEDGEMENTS}

We would like to thank the entire staff of the Medical and Statistical Archives Sector of the UFRGS Veterinary Hospital, in special Mr. Marco Rodino for his assistance with medical records access. The authors report no conflicts of interest. The authors alone are responsible for the content and writing of this paper.

\section{REFERENCES}

ACIERNO, M.J.; LABATO, M.A. Canine incontinence. Vet. Clin. Small Anim., v.49, p.125140, 2019.

APPLEGATE, R.; OLIN, S.; SABATINO, B. Urethral sphincter mechanism incompetence in dogs: An update. J. Am. Anim. Hosp. Assoc., v.54, p.22-29, 2018 
ARNOLD, S.; ARNOLD, P.; HUBLER, M.; et al. Urinary incontinence in spayed bitches: prevalence and breed predisposition. Schweiz. Arch. Tierheilkd., v.131, p.259-263, 1989.

BEAUVAIS, W.; CARDWELL, M.; BRODBELT, D.C. The effect of neutering on the risk of urinary incontinence in bitches - a systematic review. J. Small Anim. Pract., v.53, p.198-204, 2012.

BYRON, J. K.; TAYLOR, K.H.; PHILIPS, G.S.; STAHL, M.S. Urethral Sphincter Mechanism Incompetence in 163 Neutered Female Dogs: Diagnosis, Treatment, and Relationship of Weight and Age at Neuter to Development of Disease. $J$. Vet. Intern. Med., v.31, p.442-448, 2017.

BYRON, J.K. Micturition Disorders. Vet. Clin. N. Am. Small, v.45, p.769-782, 2015.

CONCANNON, P.W.; MEYERS-WALLEN, V.N. Current and proposed methods for contraception and termination of pregnancy in dog and cats. J. Am. Vet. Med. Assoc., v.198, p.1214-1225, 1991.

DE BLESER, B.; BRODBELT, D.C.; GREGORY, N.G.; MARTINEZ, T.A. The association between acquired urinary sphincter mechanism incompetence in bitches and early spaying: a case-control study. Vet. J., v.187, p.4247, 2011.

DE CESARE, T., FERRARI, S., ROMAGNOLI, S. Ocorrência de incontinência urinária em cadelas castradas no Hospital Veterinário da Universidade Anhembi-Morumbi, São Paulo, Brasil. Braz. J. Vet. Res. Anim. Sci., v.50, p.184187, 2013.

FORSEE, K.M.; DAVIS, G.J.; MOUAT, E.E. et al. Evaluation of the prevalence of urinary incontinence in spayed female dogs: 566 cases (2003-2008). J. Am. Vet. Med. Assoc., v.242, p.959-962, 2013.

GREGORY, S.P. Developments in the understanding of the pathophysiology of urethral sphincter mechanism in competence in the bitch. Br. Vet. J., v.150, p.135-150, 1994.
HEDLUND, C.S. Cirurgia dos sistemas reprodutivo e genital. In: FOSSUM, T.W. Cirurgia de pequenos animais. 3.ed. São Paulo: Roca, 2012. p.571-594.

HOELZLER, M.G.; LIDBETTER, D.A. Surgical management of urinary incontinence. Vet. Clin. N. Am. Small, v.34, p.1057-1073, 2004.

HOLT, P.E.; THRUSFIELD, M.V. Association in bitches between breed, size, neutering and docking, and acquired urinary incontinence due to incompetence of the urethral sphincter mechanism. Vet. Rec., v.133, p.177-180, 1993.

HOWE, L.M.; SLATER, M.R.; BOOTHE, H.W. et al. Long-term outcome of gonadectomy performed at an early age or traditional age in dogs. J. Am. Vet. Med. Assoc., v.218, p.217-221, 2001.

LESS, G.E. Incontinência, enurese, disúria e noctúria. In: ETTINGER, S.J.; FELDMAN, E.C. (Eds.). Tratado de medicina interna veterinária: doenças do cão e do gato. 5.ed. Rio de Janeiro: Guanabara Koogan, 2004. p.256-278.

MEDRONHO, R.A.; BLOCH, K.V.; RONIR, R.G.; WERNECK, G.L. Epidemiologia. 2.ed. São Paulo: Atheneu, 2009. 685p.

PEGRAM, C.; O’NEILL, D.G.; CHURCH, D.B. et al. Spaying and urinary incontinence in bitches under UK primary veterinary care: a case-control study. J. Small Anim. Pract., v.60, p.395-403, 2019.

PÖPPL, A.G.; CARVALHO, G.L.; VIVIAN, I.F. et al. Canine diabetes mellitus risk factors: a matched case control study. Res. Vet. Sci., v.114, p.469-473, 2017.

VAN GOETHEM, B.; SCHAEFERS-OKKENS, A.; KIRPENSTEIN, J. Making a rational choice between ovariectomy and ovariohysterectomy in the dog: a discussion of the benefits of either technique. Vet. Surg., v.35, p.136-143, 2006.

VOORWALD, F.A.; TIOSSOLL, C.F.; TONIOLLO, G.H. Urinary incontinence after gonadectomy in female dogs. Cienc. Rural, v.40, p.718-726, 2010. 